\title{
Os desassossegos de Fernando Pessoa
}

Renata Soares J unqueira*

* Universidade Estadual Paulista (UNE SP), Campus de Araraquara (SP). 
$E$, perante a realidade suprema da minha alma, tudo o que é útil e exterior me sabe a frívolo e trivial ante a soberana e pura grandeza de meus mais vivos e frequentes sonhos. Esses, para mim, são mais reais.

Vicente Guedes, Livro do Desassossego

Que os deuses todos me conservem, até à hora em que cesse este meu aspecto de mim, a noção clara e solar da realidade externa, o instinto da minha inimportância, o conforto de ser pequeno e de poder pensar em ser feliz.

Bernardo Soares, Livro do Desassossego

Não há, no mundo lusófono, crítico literário afoito nem editor audacioso que se não queira arriscar a um envolvimento com a obra de Fernando Pessoa (18881935), prodígio inegável da literatura de todos os tempos. M exendo e remexendo no famoso espólio guardado na Biblioteca Nacional de Lisboa, os estudiosos pessoanos vão trazendo a lume tanto os textos inéditos que o escritor deixou em vias de publicação quanto aqueles que ele talvez não pretendesse nunca publicar por os considerar inacabáveis ou porque não se decidia quanto à complexa questão da autoria a ser-Ihes atribuída. ${ }^{1}$ Foi deste valioso montante de papéis

\footnotetext{
R ecentemente, Teresa R ita Lopes ( 1990) revelou a existência de dezenas de "personalidades literárias" que, sem ter o estatuto de Alberto Caeiro, Ricardo R eis ou Álvaro de Campos, palpitam todavia nos misteriosos papéis que constituem o espólio de Fernando Pessoa.
} 
datilografad os e manuscritos que surgiu a espantosa série de fragmentos destinados a compor um Livro do Desassossego, editado pela primeira vez em 1982 graças ao esforço organizador de J acinto do Prado Coelho, Maria Aliete Galhoz e Teresa Sobral Cunha.

A prosa estonteante de B ernardo Soares - semi-heterônimo que Pessoa apresentara ao público letrado em 1929, nas páginas da revista Solução E ditora - caiu como uma bomba nas mãos dos críticos, que então já estavam comodamente habituados a ler a poesia do ortônimo e dos três célebres heterônimos. Eduardo Lourenço, pasmado pelo que o Livro do Desassossego tinha de "texto agónico" ou "texto suicidário" (L OURE NÇO, 1986, p. 91) fadado a mostrar a "encenação abismal do E u como ausência radical de si mesmo e do mundo" (ibid., p. 86), não tardou a lançar a este respeito um vaticínio certeiro: “... de uma caoticidade textual empírica, embora condicionada pela intenção expressa de Pessoa (quando existe), os editores fizeram um livro. Que mais não fosse, por isso, suscitaram um desassossego semântico e hermenêutico que nunca mais o largará" (ibid., p. 84).

$M$ as até então só se falava no Livro do Desassossego composto por B ernardo Soares, ajudante de guarda-livros na cidade de Lisboa. O que o crítico de Vence não podia adivinhar é que a incansável Teresa Sobral Cunha publicaria em 1991, com a chancela "E ditorial Presença”, uma nova versão do Livro, agora organizado por ela em dois volumes destinados a marcar a dupla autoria que é preciso não ignorar: afinal, o Livro do Desassossego foi de fato atribuído a Bernardo Soares, mas também, antes dele, a um outro heterônimo de nome Vicente Guedes. Mais longe ainda estava E duardo L ourenço de adivinhar que, em 1994, a mesma Teresa Sobral Cunha lançaria no Brasil, pela Editora da UNICAMP, a chamada "versão integral" do Livro, que apresenta fragmentos inéditos de Vicente Guedes² tendentes a novamente demonstrar - valham-nos as palavras do apresentador desta edição brasileira - que "a questão 'Vicente G uedes' não pode ser mais escamoteada das edições do Livro tal foi o empenho de Pessoa na configuração de uma sua fisionomia" (OSAKABE, 1994, p. 8). E agora? Qual será o desassossego dos críticos diante desta ( pessoaníssima) dificuldade adicional? O que dirá E duardo Lourenço, que considera a voz de Bernardo Soares como a que mais se aproxima da verdadeira voz - sem fingimento - de Fernando Pessoa e que afirma ser a obra do ajudante de guarda-livros "a menos mascarada, a menos ficcional de um autor que teve a obsessão de nos prevenir que para ele, ou para quem o leia, tudo é máscara" (LOURE NÇO, 1986, p. 87)? Não teremos aqui um jogo de máscaras ainda mais densas do que as dos três heterônimos "clássicos"? Não estará o autor de

Tenho notícias de que T. S. Cunha organizou finalmente uma "versão canónica" dos dois volumes do Livro do Desassossego, dados à luz recentemente pela editora lisboeta R elógio d'Água. Ali aparecem novos fragmentos inéditos de Vicente Guedes. 
Fernando, rei da nossa Baviera correndo o risco de cair, também ele, numa das armadilhas de Pessoa? Ponderemos.

A questão é delicada e será prudente relembrar os primórdios da crítica ao Livro do Desassossego. Foi J orge de Sena o primeiro a debruçar-se sobre os fragmentos do Livro no espólio e o primeiro a pensar na edição para a qual chegou a preparar uma "Introdução" que hoje deve ser texto de leitura obrigatória para os mais conspícuos estudiosos de Fernando Pessoa. Ali o crítico chama a atenção para um aspecto contextual que, a meu ver, merece destaque - sobretudo quando se fala de Fernando Pessoa. Os modernistas, diz ele,

"precisavam de agredir e de enganar todo um sistema sócio-estético que assentava na mistificação da sinceridade (equivalente à do representativismo burguês), e não podiam fazê-lo senão, como toda a noção de dialéctica nos ensina, praticando a mistificação da mistificação como mistificação." (SE NA, 1982, p. 187; grifo meu)

De resto, é preciso não esquecer que Fernando Pessoa foi educado "sob os influxos literários do simbolismo francês e do esteticismo britânico" (SE NA, 1982, p. 186) e que, portanto,

“sabia muito bem a que ponto uma obra de arte não é, precisamente por ser obra de arte, o próprio artista, mas um objeto estético, em cuja confecção a experiência humana do artista entra a igual título que os ritmos, as significações complexas e contraditórias, as ideias, a linguagem." (SE NA, 1982, p. 186)

Parece, todavia, que a notável acuidade do pensamento de J orge de Sena não o exime também de um lapso ou - o que é muito pior - de cometer uma grave injustiça. Pois é precisamente àqueles movimentos literários do fim do século passado, dos quais Pessoa teria herdado "o interesse pela linguagem enquanto vivência estética" (SENA, 1982, p. 190) e o hábito do "exercício da criação de 'personagens' que sejam, ao mesmo tempo, mais personagens e menos personagens" (ibid., loc. cit.) do que os próprios poetas que as criam - é precisamente àqueles esteticismos, aos quais Pessoa devia, enfim, a sua "consciência de si mesmo como artista" (ibid., p. 198), que J orge de Sena vai atribuir a culpa do falhanço que foi, segundo ele, o Li vro do Desassossego na sua primeira fase de elaboração - a fase de Vicente Guedes -, livro anacrônico, "literário por de mais" (ibid., p. 207), produto de um "simbolismo exagerado e sediço" que os três heterônimos maiores (responsáveis, estes sim, pela grandeza de Fernando Pessoa) "crestavam com o seu fogo ou o seu gelo" (ibid., p. 206).

Ora, se de Pessoa se pode dizer que a "tão espantosa e tão exemplar ciência de não-ser" (SE NA , 1982, p. 181), com que ele combateu denodadamente o indivi- 
dualismo romântico e exerceu decididamente a sua modernidade, tem raízes firmes no Simbolismo e nos artificialismos que este movimento propagandeou, então é injusto ou mesmo contraditório conceber de maneira maniqueísta - e com adjetivação nitidamente sintomática desse maniqueísmo - a "transformação do Pessoa esteticista e simbolista, no grande modernista que ele foi" (ibid., p. 198).

Seja como for - justa ou não - , a opinião de J orge de Sena acerca do "livro" escrito por Vicente Guedes é a de que ele não passa de um rascunho falhado, um projeto abandonado pelo demiurgo Fernando Pessoa em nome da modernidade do "verdadeiro livro do verdadeiro desassossego" (SENA, 1982, p. 206), composto por B ernardo Soares, ajudante de guarda-livros na cidade de Lisboa. ${ }^{3}$

É outra a perspectiva de Eduardo Lourenço, que aliás parece ter elaborado boa parte das suas reflexões sobre o Livro do Desassossego como contraposição à crítica pioneira de J orge de Sena. E mbora admita que “um mundo parece separar os vários textos vinculados à estética simbolista e hiper-simbolista dos outros que são a maioria e constituem os grandes textos-fragmentos de 'O Livro do Desassossego' ", L ourenço (1986, p. 91-2) ultrapassa as aparências e considera que, em última análise, a diferença entre Vicente Guedes e Bernardo Soares não vai além de uma questão de "escrever a mesma vivência de oposta maneira": é o "mesmo sentimento do nada" que Soares inscreve "no coração do real trivialíssimo" e que Guedes prefere registrar a partir de uma "assumpção simbólica abstracta" desse mesmo real. O que salta aos olhos, tanto num como noutro, é a descoberta espantosa e angustiante da "imobilidade existencial" (LOURENÇO, 1986, p. 91), do "sem-sentido absoluto e do naufrágio" (ibid., p. 16) inevitável de tudo o que constitui a nossa vida e o mundo em que vivemos.

Deste ponto de vista, "não há diferença entre textos como a Floresta do Alhea mento anteriores à eclosão heteronímica e textos do ano da sua [ de Pessoa] vera morte" (L OURE NÇO, 1986, p. 91). Mas o crítico ainda vai mais longe: acredita que "Caeiro, Campos, Reis, não são mais que sonhos diversos, maneiras diferentes de fingir que é possível descobrir um sentido para a nossa existência, saber 
quem somos, imaginar que conhecemos o caminho e adivinhamos o destino que vida e história nos fabricam" (LOURE NÇO, 1986, p. 19), e conclui, todavia, que "ter sonhado esses sonhos não libertou Pessoa da sua solidão e da sua tristeza" (ibid., loc. cit.). Ora, tudo isso seria inteiramente razoável se Lourenço não tivesse cedido à tentação de identificar a solidão e a tristeza de Fernando Pessoa com os mesmos sentimentos patentes no seu semi-heterônimo Bernardo Soares, que afinal não passaria de um "pseudo-semi-heterónimo" ( L OURE NÇO, 1986, p. 93) ou de uma "mal fingida máscara" (ibid., p. 86). E sta inesperada interpretação transforma capciosamente a afirmação de que Pessoa sonhou os seus heterônimos - as suas "ficções do interlúdio", como ele mesmo os designava - numa afirmação de natureza bem diversa: ao fim das contas - pasmem! -, "quem sonhou todas estas ficções foi o passeante da Rua dos Douradores, um homem triste por não existir como se sonhava, irmão gémeo por dentro de Luís da B aviera, prisioneiro como ele de idênticos fantasmas" (LOURENÇO, 1986, p. 19).

Assim, Eduardo Lourenço enreda-se - e quase nos enreda também - num complexo de relações de parentesco que se formula numa equação de três termos: Bernardo Soares, ajudante de guarda-livros num escritório da Rua dos Douradores, é irmão gêmeo por dentro do rei Luís II da Baviera, que é irmão gêmeo por dentro de Fernando Pessoa, correspondente estrangeiro em casas comerciais. A figura simbólica do triste rei sonhador e perdulário, que abandona a política para se embevecer com a construção de castelos e com a arte de Richard Wagner, é a pedra-de-toque que, garantindo a analogia, viabiliza a equação com a qual o crítico assume, muito lucidamente, uma posição inversa àquela já assumida por J orge de Sena: em vez de valorizar os aspectos propriamente modernistas da obra de Pessoa, contrapostos ao que do Simbolismo nela ainda persistia, Lourenço considera, apoiado no Livro do Desassossego, que o mais autêntico Fernando Pessoa é essencialmente simbolista e que o "vanguardismo" aparente da sua multifacetada obra é apenas superficial:

"O Livro do Desassossego desarticula todas as ficções que o [Fernando Pessoa] separaram em vão do único amor que o habitou, herói de Wagner sem legenda, o da própria Morte. É à luz, agora soberana, do Livro do Desassossego que todo o texto - falsamente plural - de Fernando Pessoa deve ser relido. Aí está o retábulo da sua vera e incruenta paixão. É um retábulo simbolista pouco conforme ao mito-Pessoa de um vanguardismo estridente e todo exterior, mas talvez esse mito seja mais do nosso engano que da sua verdade. Toda a sua vida foi si mbolista. Nem há na literatura do Ocidente mais completa expressão do Simbolismo. O Modernismo foi a sua e nossa ficção. Devolvamo-lo ... à sua verdade-ficção, à sua dolorosa realidade de amante da Morte, de herói da impossibilidade de amar como o seu duplo e não menos wagneriano Luís Segundo, Rei da Baviera..." (LOURE NÇO, 1986, p. 19-20; grifo meu) 
Como sairemos nós deste dilema? Tomaremos o partido de J orge de Sena ou o de E duardo L ourenço? Terá alguma razão o crítico de Vence? Terá muita, decerto: relativamente ao Simbolismo, E duardo Lourenço apresenta-se com vantagem porque a sua posição parece isenta de preconceitos que J orge de Sena nem explica nem se esforça por disfarçar. M as quanto a considerar o Li vro do Desassossego como a obra menos mascarada de Fernando Pessoa e a identificar a voz de B ernardo Soares como a que mais se aproxima da verdadeira voz do homem triste e solitário que foi Fernando Pessoa (artista que, é verdade, chegou mesmo a quase abdicar da vida para viver essencialmente em li teratura) - aí já temos outros quinhentos que talvez só uma nova leitura nos possa ajudar a contar. Consultemos, pois, a edição brasileira do Livro do Desassossego (LD) (PESSOA, 1994, 2v), organizado por Teresa Sobral Cunha.

É bom começar lembrando que, em 1929, ao apresentar na revista Solução Editora ( $n$ - 2) o primeiro trecho do Livro do Desassossego atribuído a B ernardo Soares, Fernando Pessoa já classificava o autor como um seu "semi-heterônimo" porque, segundo a explicação que seria dada nas páginas introdutórias das suas Ficções do Interlúdio,

“... B ernardo Soares, distinguindo-se de mim por suas ideias, seus sentimentos, seus modos de ver e de compreender, não se distingue de mim pelo estilo de expor. Dou a personalidade diferente através do estilo que me é natural, não havendo mais que a distinção inevitável do tom especial que a própria especialidade das emoções necessariamente projecta." (LD, v. 2, p. 9)

À conta dessa parecença de estilos, Soares seria excluído das Ficções do Interlúdio e, curiosamente, embora Ihe fosse publicamente atribuída a autoria do Li vro do Desassossego, quem subscrevia os trechos que desta obra apareceram na revista Solução E di tora ( $n 02$ e 4, 1929), no no 34 da Presença (nov. 1931- fev. 1932), no jornal Revolução de 6/6/32 e em A Revista ( $n$ o 1, 1932) não era o semi-heterônimo mas sim o próprio Fernando Pessoa. ${ }^{4}$

Em que pesem as aparências, o que entretanto os dois volumes organizados por Teresa Sobral Cunha evidenciam é o quanto há de deliberado artificialismo na construção desse semi-heterônimo que parece muito mais um sofisticado

4 Essa embaraçosa semi -heteroními a terá sido, provavelmente, uma das causas da desconfiança de $E$ duardo $L$ ourenço, que afinal o levaria a interpretar o Livro do Desassossego como a obra “menos ficcional” (LOURE NÇO, 1986, p. 87) dentre todas as de Pessoa. Quanto mais não seja, Pessoa mesmo confessara, nas páginas introdutórias às Ficções do Interlúdio, que "em prosa é mais difícil de se outrar" (LD, v. 2, p. 9). E a confusão ainda pode ser maior se lembrarmos que, na carta de 13/1/35 em que explica a Casais M onteiro o aparecimento dos heterônimos, Pessoa se refere a B ernardo Soares como “um semi-heterónimo porque, não sendo a personalidade a minha, é, não diferente da mi nha, mas uma simples mutilação dela. Sou eu menos o raciocínio e a afectividade" (Pessoa apud SE NA, 1982, p. 233; grifo meu). 
implemento teatral do "drama-em gente" de Fernando Pessoa do que uma "versão" mal disfarçada do próprio Fernando Pessoa. Se não, vejamos.

Vicente Guedes foi quem primeiramente Pessoa idealizou como autor do Livro do Desassossego. A ele foram atribuídos diversos fragmentos da obra, dos quais os mais densos e mais conhecidos são "Na floresta do alheamento" - publicado no volume IV da revista A Águia, de 1913 - e "M archa fúnebre para o rei L uís Segundo da B aviera". Guedes é "fisicamente desajeitado e inaceitável" mas sem "aquele grau de amarfanhamento orgânico com que entre na órbita da compaixão alheia" ( LD, v. 1, p. 203), e é também - por defeito de fabricação, como logo veremos - "ajudante de guarda-livros" ou "empregado do comércio" na Rua dos Retrozeiros, n 17, 40 andar, em Lisboa ( LD, v. 1, p. 192).

$\mathrm{Na}$ verdade, Vicente Guedes é absolutamente indiferente à "compaixão alheia" e a tudo o que o cerca. Tem alma de dandy, como explica Fernando Pessoa no "P refácio" que chegou a preparar para a primeira versão do Li vro: G uedes "criou definitivamente a aristocracia interior, aquela atitude de alma que mais se parece com a própria atitude de corpo de um aristocrata completo" (LD, v. 1, p. 19). Isolou-se do mundo num apartamento de 4o andar da Baixa lisboeta, morada que mobilou com requinte decadente - "cuidara especialmente das cad eiras - de braços, fundas, moles -, dos reposteiros e dos tapetes" (LD, v. 1, p. 17-8) -, requinte adequado "para manter a dignidade do tédio", segundo dizia ( LD, v. 1, p. 18). A única sociedade em que viveu foi a que ele mesmo imaginou no seu vasto mundo interior ou aquela que concebeu literariamente porque, afinal,

“Há metáforas que são mais reais do que a gente que anda na rua. Há imagens nos recantos de livros que vivem mais nitidamente que muito homem e muita mulher. Há frases literárias que têm uma individualidade absolutamente humana. Passos de parágrafos meus há que me arrefecem de pavor, tão nitidamente gente eu os sinto, tão recortados de encontro aos muros do meu quarto, na noite, na sombra (...) Tenho escrito frases cujo som, lidas alto ou baixo - é impossível ocultar-Ihes o som - é absolutamente o de uma coisa que ganhou exterioridade absoluta e alma inteiramente." (LD, v. 1, p. 105)

Com tamanha sensibilidade estética, tão habituado a "sentir o falso como o verdadeiro, o sonhado tão nitidamente como o visto" (LD, v. 1, p. 105), Guedes confessa ter perdido "a distinção humana ... entre a verdade e a mentira" (LD, v. 1, p. 106). Assim, despreza o mundo exterior, que considera "um pesadelo inestético" ( $L D, v .1$, p. 79), detesta a vida prática e repudia decididamente todo o utilitarismo burguês - "detesto o útil”, lê-se a páginas tantas do seu Livro (LD, v. 1, p. 130).

Ora, o Livro que Vicente G uedes se compraz em escrever é, na realidade, o que o mantém vivo - é o lugar, por excelência, da plena realização da sua “atitude natural 
de insinceridade" (LD, v. 1, p. 149), da sua vocação de fantasista ou sonhador inadaptável à vida comum. Trata-se, aparentemente, de um diário ínti mo composto de fragmentos incompletos, "apontamentos espirituais" ( LD, v. 1, p. 190) que às vezes se parecem com cartas que o autor escreveu apenas para se entreter porque, segundo ele, "Só as cartas comerciais são dirigidas. Todas as outras devem, pelo menos para o homem superior, ser apenas dele para si próprio" (LD, v. 1, p. 134).

Mas Guedes não é propriamente um egocêntrico à maneira romântica. Pelo contrário, parece possuir um ego pulverizado e declara não saber ao certo quais são as suas idéias, os seus sentimentos, o seu caráter (cf. LD, v. 1, p. 145):

“Tenho as opiniões mais desencontradas, as crenças mais diversas. É que nunca penso, nem falo, nem ajo... Pensa, fala e age por mim sempre um sonho qualquer meu em que me encarno de momento...

De meu, só sinto uma incapacidade enorme, um vácuo imenso, uma incompetência ante tudo quanto é a vida. Não sei os gestos a acto nenhum real (...)

Nunca aprendi a existir." (LD, v. 1, p. 144)

Assim, a existência que Vicente G uedes contempla é tão-somente a existência em sonho - e o Livro do Desassossego que ele escreve apresenta-se, em última análise, como um desfigurado precei tuári o estéti co: uma espécie de propaganda, falsamente despretensiosa, da estética do sonho ou estética do artifício. "Pregador da renúncia" (LD, v. 1, p. 115) convicto e confesso, G uedes só sabe dar às suas pregações o tom do "que nada ... nos cure do prazer quase-espasmo de mentir" (LD, v. 1, p. 26).

Estamos, portanto, diante de um esteticista exemplar e de um simbolista que não esconde a sua wagneriana afeição por Luís da B aviera, símbolo maior da renúncia, "Rei do Desapego", "Imperador da Morte e do Naufrágio, sonho vivo errando, faustoso, entre as ruínas e os exílios do mundo" (LD, v. 1, p. 55). E estamos também diante de uma incongruência que Fernando Pessoa terá decerto notado porque oportunamente a emendou: não condiz nada com um temperamento tão i mpecavelmente aristocrata como o de Vicente Guedes a banal profissão de ajudante de guarda-livros - que ele, de resto, não assume em momento nenhum. Para garantir a coerência da ficção, seria preciso alterar a personalidade criada ou então mudar a sua ocupação. Pessoa optou por manter a ocupação, deixando de Iado o heterônimo Vicente Guedes e o seu Livro do Desassossego que, por esta razão, se apresenta mais visivelmente fragmentário e incompleto do que aquele outro que seria, a partir de 1929, atribuído a B ernardo Soares.

Mas não nos admire a insistência de Pessoa na profissão de "ajudante de guarda-livros". Isto é compreensível porque, por maiores que fossem as suas afini- 
dades com o Simbolismo - elas eram mesmo grandes e, até onde posso julgar, Eduardo Lourenço está coberto de razão no que toca a esta questão -, não se pode todavia esquecer que foi ele um dos iniciadores do Modernismo em Portugal. Pessoa não era indiferente ao espírito da sua época e há de ter reconhecido que, às portas da década de 1930, pareceria já insustentavelmente anacrônica uma aristocracia tão inabalável como a de Vicente Guedes. Assim como a nobreza não pôde resistir à espantosa ascensão da burguesia da era industrial, Fernando Pessoa não pôde deixar de substituir Vicente Guedes - que sonhava à vontade no interior de um apartamento luxuosamente mobilado - por B ernardo Soares - triste (e efetivo) contabilista condenado a sonhar tão intensamente quanto Guedes, mas ora no interior acanhado de um escritório de armazém de fazendas situado na Rua dos Douradores, na B aixa lisboeta, ora "no seu quarto alugado" (LD, v. 2, p. 14) , guarnecido de "mobília tosca" ( LD, v. 2, p. 30) e localizado num 4o andar da mesma Rua dos Douradores.

A substituição é feita a contrapelo, evidentemente. Logo no "P refácio" ao seu Li vro do Desassossego, B ernardo Soares critica o advento do Romantismo e a instituição da democracia moderna, lamentando a "ruína da influência aristocrática" ( LD , v. 2, p. 17). Porém, como a realidade burguesa se impõe inapelavelmente, a modesta condição de "ajudante de guarda-livros" será o fundamento mesmo da criação da personalidade deste semi-heterônimo que quase não vê limites entre o lugar onde trabalha e o lugar da sua inti midade (repare-se que escritório e morada se situam, ambos, no mesmo âmbito da Rua dos Douradores). É como se ele não pudesse existir senão como ajudante de guarda-livros na cidade de Lisboa - e ele mesmo afirma, com amarga consciência, que se "tivesse o mundo na mão, trocava-o ... por um bilhete para [a] Rua dos Douradores" (LD, v. 2, p. 270). Dado este parti pris, a criação do novo autor do Livro do Desassossego passa a fazer-se com notável desembaraço na articulação dos diversos elementos - físicos, psíquicos e morais - constitutivos da sua personalidade.

Soares tem um "metro e setenta de altura", pesa "sessenta e um quilos" (LD, v. 2, p. 289), aparenta trinta anos, tem a face pálida com ar de sofrimento e vestese "com um certo desleixo não inteiramente desleixado" (LD, v. 2, p. 13). Não se lembra da mãe, que morreu quando ele tinha um ano, nem chegou a conhecer o pai, que vivia longe e que se matou dois anos depois de ter morrido a mãe (cf. LD, v. 2, p. 31-2). Acredita que ter ficado órfão tão cedo foi a causa da sua "indiferença sentimental" ( LD , v. 2, p. 32), mas afinal se considera "feliz por não ter já parentes" e não se ver "assim na obrigação ... de ter que amar al guém" ( LD, v. 2, p. 267). A sua indiferença sentimental, quanto mais não seja, é o que está na origem do seu obstinado pendor intelectual e do seu assumido esteticismo: 
“Tenho para com tudo que existe uma ternura visual, um carinho da inteligência - nada no coração. Não tenho fé em nada, esperança de nada, caridade para nada. Abomino com náusea e pasmo os sinceros de todas as sinceridades e os místicos de todos os misticismos...

Não tenho saudades senão literariamente. Lembro a minha infância com lágrimas, mas são lágrimas rítmicas, onde já se prepara a prosa." (LD, v. 2, p. 267)

Com efeito, a privação de afetos familiares parece ter levado B ernardo Soares a apegar-se ao universo de relações que a sua fantasia Ihe concede e a afeiçoarse, sobretudo, aos artifícios da linguagem pela qual os seus sonhos se exprimem. Assim, mais que essencial à sua vida, a prosa que el e escreve é quase a sua identidade mesma que, se se insinua quando ele declara que "minha pátria é a língua portuguesa" ( LD, v. 2, p. 281), se revela mais abertamente quando admite que

“Sou, em grande parte, a mesma prosa que escrevo. Desenrolo-me em períodos e parágrafos, faço-me pontuações, e, na distribuição desencadeada das imagens, visto-me, como as crianças, de rei com papel de jornal, ou, no modo como faço ritmo de uma série de palavras, me touco, como os loucos, de flores secas que continuam vivas nos meus sonhos. $\mathrm{E}$, acima de tudo, estou tranquilo, como um boneco de serradura que, tomando consciência de si mesmo, abanasse de vez em quando a cabeça, para que o guiso [sic] no alto do boné em bico ( parte integrante da mesma cabeça) fizesse soar qualquer coisa, vida tinida do morto, aviso mínimo ao Destino." (LD, v. 2, p. 255; grifo meu)

Nisto as duas versões do Livro do Desassossego são muito parecidas - a segunda é também, como a primeira, um preceituário estético dissimulado, onde se prega a renúncia de tudo o que não seja "contemplação estética da vida" (LD, v. 2, p. 22). Tal e qual Vicente Guedes, B ernardo Soares escreve "como quem dorme" ( $L D$, v. 2, p. 98) e considera que a "literatura é a maneira mais agradável de ignorar a vida" ( LD, v. 2, p. 141). Para ambos a "vida é oca, a alma é oca, o mundo é oco. Todos os deuses morrem de uma morte maior que a morte. Tudo está mais vazio que o vácuo. É tudo um caos de coisas nenhumas" (LD, v. 2, p. 258).

$M$ as aqui convém lembrar que, diferentemente de $G$ uedes, B ernardo Soares não é homem de um livro só. A par do seu Livro do Desassossego - coleção de "impressões sem nexo, nem desejo de nexo" em que ele narra a sua "autobiografia sem factos", a sua "história sem vida" (LD, v. 2, p. 47) -, compõe ainda o livro comercial do escritório em que trabalha, livro de números que também o acompanha durante toda a sua vida (cf. LD, v. 2, p. 92). E é esta, precisamente, a sua tragédia: ser naturalmente um sonhador e socialmente um contabilista; ser escri tor e também, por força, escrevente. Ele mesmo declara, com profunda amargura: "Nunca tive dinheiro para poder ter tédio à vontade..." (LD, v. 2, p. 201). 
Assim, Soares pode apenas identificar-se "em grande parte" - mas não inteiramente - com os sonhos que concebe e com a prosa que escreve. E $\mathrm{m}$ parte ele é prosa, em parte é números e cálculos. O cotidiano rasteiramente burguês que ele vai vivendo na Lisboa da década de 1930 constitui também, em larga medida, a sua personalidade:

"Se houvesse de inscrever, no lugar sem letras de resposta a um questionário, a que influências literárias estava grata a formação do meu espírito, abriria o espaço ponteado com o nome de Cesário Verde, mas não o fecharia sem nele inscrever os nomes do patrão Vasques, do guarda-livros M oreira, do Vieira caixeiro de praça e do António moço do escritório. E a todos poria, em letras magnas, o endereço-chave LISBOA." (LD, v. 2, p. 207)

É , de resto, a ocupação rasteira de contabilista que o prende ao mundo real e que faz dele um observador do espaço urbano tão lúcido quanto Cesário Verde um flâneur da cidade de Lisboa que, para se expressar, substitui o verso pela prosa. É a imprescindível função de ajudante de guarda-livros que, surpreendentemente, Ihe confere o potencial de escritor moderno, dividido entre o espetáculo dos sonhos que a sua própria alma Ihe oferece como um "teatro íntimo" (LD, v. 2, p. 92) e aquele outro espetáculo, todo exterior, que lhe é dado pelo "colorido variadíssimo de Lisboa" ( LD, v. 2, p. 273) com os seus "casais futuros, ... os pares das costureiras, ... rapazes com pressa de prazer, ... os reformados de tudo, ... os vadios parados que são donos das lojas" (LD, v. 2, p. 51), a "gente que se apinha onde o antigo teatro espelha luz na rua larga" ( LD, v. 2, p. 68), "os arruamentos, os letreiros, as pessoas vestidas e falando, os empregos, os jornais..." (LD, v. 2, p. 60), e também - ainda que isto lhe pese - os "veículos, ... os produtos da ciência telefones, telégrafos - que tornam a vida fácil, ou os subprodutos da fantasia gramofones, receptores hertzianos - que, aos a quem divertem, a tornam divertida" (LD, v. 2, p. 273). É , enfim, a sua condição si ne qua non de passeante da Rua dos D ouradores que o distingue sensivelmente de Vicente $G$ uedes porque faz dele, menos que um livre sonhador, um "intervalo ... entre o que sonho e o que a vida fez de mim" (LD, v. 2, p. 263):

“Há momentos em que cada pormenor do vulgar me interessa na sua existência própria, e eu tenho por tudo a afeição de saber ler tudo claramente. E ntão vejo ... o comum com singularidade, e sou poeta com aquela alma com que a crítica dos gregos formou a idade intelectual da poesia. M as também há momentos, e um é este que me oprime agora, em que me sinto mais a mim que às coisas externas, e tudo se me converte numa noite de chuva e lama, perdido na solidão de um apeadeiro de desvio, entre dois comboios de terceira classe." (LD, v. 2, p. 75) 
Em quaisquer desses momentos, aflora sempre em Bernardo Soares uma intuição de que "todos nós, que sonhamos e pensamos, somos ajudantes de guarda-livros num Armazém de fazendas, ou de outra qualquer fazenda em uma Baixa qualquer" (LD, v. 2, p. 78). I mpõe-se-Ihe a cada instante um pressentimento do nonsense insofismável de tudo - sejam os sonhos, seja o real cotidiano: “E penso se a minha voz, aparentemente tão pouca coisa, não incarna a substância de miIhares de vozes, a fome de dizerem-se de milhares de vidas, a paciência de milhões de almas submissas como a minha ao destino quotidiano, ao sonho inútil, à esperança sem vestígios" (LD, v. 2, p. 41).

Descrente, portanto, de toda e qualquer ação, Soares dedica a sua vida ao único ato que lhe parece válido - justamente porque lhe assegura refúgio: quer quando registra números num livro comercial, quer quando compõe os "versos em prosa" ( LD, v. 2, p. 264) do seu Livro do Desassossego, é ao ato de escrever que ele se restringe: "Achego-me à minha secretária como a um baluarte contra a vida" ( LD, v. 2, p. 41). Neste aspecto ele é, sem dúvida, tão exemplarmente esteticista quanto Vicente Guedes - e aqui retornamos nós à hipótese de E duardo Lourenço, que julga não haver diferença essencial entre os fragmentos do Livro escritos por volta de 1913 e aqueles compostos a partir de 1929.

Mas precisamente porque é evidente o "alheamento" esteticista tanto em Guedes quanto em Soares, e precisamente porque este último não se cansa de afirmar que não é "ninguém, absolutamente ninguém" (LD, v. 2, p. 297), que não é senão "uma figura de livro, uma vida lida" (LD, v. 2, p. 256), artificialmente construída "a ouro e sedas, em salas supostas, palco falso, cenário antigo, sonho criado entre jogos de luzes brandas e músicas invisíveis" ( LD, v. 2, p. 275) - precisamente por isso será precipitado considerar a obra do passeante da Rua dos D ouradores como a menos mascarada ou menos ficcional no universo literário do demiurgo Fernando Pessoa. A final, o Livro de B ernardo Soares parece distinguirse de um journal intime como o de Henri Frédéric A miel sobretudo pela eficiência dos artifícios delinguagem ou dos "bons momentos verbais" ( LD, v. 2, p. 260) , que no texto do suíço sucumbem a uma "insuportável interiorice" (LD, v. 2, p. 260).

Contudo, se vale a pena insistir na tese segundo a qual o Livro do Desassossego é, de fato, acentuadamente autobiográfico, porque Fernando Pessoa também, ele mesmo, sempre se empenhou em transformar-se em ficção, e advertidamente classificou Bernardo Soares como um semi -heterôni mo apenas, e ainda tomou a liberdade de inserir no Livro "uma carta real ... dirigida a sua M ãe" (LOURENÇO, 1986, p. 87) ${ }^{5}$ - então, que ao menos sejam as seguintes as primeiras pala-

5 Trata-se da cópia da carta datada de 5/6/1914, que Fernando Pessoa destinou à sua mãe, que então se encontrava em Pretória, na África do Sul (cf. LD, v. 1, p. 118-9). 
vras a transferirem-se, experimentalmente, da boca (ou da pena) de Soares para a de Pessoa: “Tenho sido actor sempre, e a valer. Sempre que amei, fingi que amei, e para mim mesmo o finjo" (LD, v. 2, p. 282).

\section{R eferências bibliográficas}

LOPES, Teresa Rita. Pessoa por conhecer: roteiro para uma expedição / textos para um novo mapa. 1. ed. Lisboa: Estampa, 1990. 2v.

LOURENÇO, Eduardo. Fernando, rei da nossa Baviera. Lisboa: I mprensa Nacional-Casa da Moeda, 1986. 146p. (Temas portugueses).

OSAKABE, Haquira. Apresentação. In: PESSOA, F. Livro do desassossego / por Vicente Guedes e Bernardo Soares. Campinas: Editora da UNICAM P, 1994. v. 1, p. 7-13.

PESSOA, Fernando. Livro do desassossego / por Vicente Guedes e B ernardo Soares: versão integral. Org. T. S. Cunha. Campinas: E ditora da UNICAM P, 1994. 2v. (Viagens da voz).

SENA, J orge de. Introdução ao Livro do Desassossego. In: . Fernando Pessoa \& $c^{\underline{a}}$ heteróni ma: estudos coligidos 1940-1978. Lisboa: E dições 70, 1982. v. 1, p. 177-242. (O bras de J orge de Sena).

\section{Bibliografia}

PESSOA, Fernando. Alguma prosa. Org. C. B erardinelli. 5. ed. R io de J aneiro: Nova Fronteira, 1990. 247p.

PESSOA, Fernando. Livro do desassossego / por B ernardo Soares. Org. J. P. Coelho, recolha e transcrição de M. A. Galhoz e T. S. Cunha. Lisboa: Ática, 1982. 321p. (Obras completas de Fernando Pessoa).

PESSOA, Fernando. Livro do desassossego / por Vicente Guedes e B ernardo Soares. Org. T.

S. Cunha. 1. ed. Lisboa: Presença, 1990. 2v.

PESSOA, Fernando. Páginas sobre literatura e estética. Org. A. Quadros. Mem Martins: E uropa-América, 1986. 240p. (Livros de bolso Europa-América, 475).

PESSOA, Fernando. Poemas completos de Alberto Caeiro. Org. T. S. Cunha. 1. ed. Lisboa: Presença, 1994. 351p. (Ler Pessoa).

PESSOA, Fernando. Poemas escolhidos. Org. J. F. Lourenço. Lisboa: Ulisseia, 1985. 364p. (Biblioteca Ulisseia de autores portugueses, 21). 